\title{
A clinical protocol for intraoral digital impression of screw-retained CAD/CAM framework on multiple implants based on wavefront sampling technology
}

\author{
Moreno, Angel ; Giménez, Beatriz ; Ȯzcan, Mutlu ; Pradíes, Guillermo
}

\begin{abstract}
PURPOSE: To obtain an accurate CAD/CAM metal framework over 6 implants using a Chairside Intraoral Scanner based on the principle of active (optical) wavefront sampling. MATERIAL AND METHODS: Six prototype cylindrical scan bodies screwed in the implants were used to obtain an intraoral digital impression. A conventional resin tooth try-in was fabricated and digitized with an extraoral scanner, and this dataset was merged to the digital data obtained from the intraoral impression to calculate the best framework design with advanced CAD software. The framework was fabricated with a 5-axis computer numerical control milling unit. Three clinical tests (saliva intrusion, Sheffield test, and screw resistance test) were performed to assess the fit of the framework. RESULTS: Under 3 clinical tests, an accurate fit was observed. CONCLUSION: The case presented in this report proposes a new clinical protocol for obtaining accurate digital impressions of multiple implants.
\end{abstract}

DOI: https://doi.org/10.1097/ID.0b013e3182980fe9

Posted at the Zurich Open Repository and Archive, University of Zurich

ZORA URL: https://doi.org/10.5167/uzh-89902

Journal Article

Accepted Version

Originally published at:

Moreno, Angel; Giménez, Beatriz; Ȯzcan, Mutlu; Pradíes, Guillermo (2013). A clinical protocol for intraoral digital impression of screw-retained CAD/CAM framework on multiple implants based on wavefront sampling technology. Implant Dentistry, 22(4):320-325.

DOI: https://doi.org/10.1097/ID.0b013e3182980fe9 
AUTHORS: Angel Moreno, DDS*, Beatriz Giménez, DDS**, Mutlu Özcan, DDS, Dr Med Dent, PhD***, Guillermo Pradíes DDS, PhD, ****

\section{ABSTRACT: (137 words)}

Purpose: To test clinically the possibility to obtain an accurate CAD/CAM implant framework over 6 implants using a Chairside Intraoral Scanner based on the principle of active (optical) wavefront sampling. Material and methods: A digital impression was taken using six prototype cylindrical scan bodies. A conventional resin teeth try-in was made and digitized with an extraoral scanner. The virtual teeth try-in was overlapped with the digital data obtained with intraoral impression in order to calculate the best structure design. The framework was fabricated with a five-axis computer numerical control (CNC) milling unit. Under standard clinical tests an accurate fit was observed at the point of screwing the framework over the implants in the patient's mouth. The present protocol described could establish the beginning of a new clinical approach to obtain accurate digital impression of multiple implants.

KEY WORDS: Intraoral scanner, digital impression, CAD/CAM, implant framework, passive fit, implantsupported prosthesis, screw-retained, digital dentistry, stereolithography, SLA model.

* Medical Director of Bista Eder Private Practice. Clínica dental Bista Eder, Eibar, Guipuzcoa, Spain.

${ }^{* *}$ Research Student, Dept. of Buccofacial Prosthesis, Faculty of Odontology, University Complutense of Madrid, Madrid, Spain.

${ }^{* * *}$ Professor, Head of Dental Materials Unit, University of Zürich, Center for Dental and Oral Medicine, Clinic for Fixed and Removable Prosthodontics and Dental Materials Science, Zurich, Switzerland.

${ }^{* * * *}$ Professor, Associate Dean, Dept. of Buccofacial Prosthesis, Faculty of Odontology, University Complutense of Madrid. 
Reprint requests and correspondence to: Mutlu Özcan, $\mathrm{PhD}$, University of Zürich, Head of Dental Materials Unit, Center for Dental and Oral Medicine, Clinic for Fixed and Removable Prosthodontics and Dental Materials Science, Plattenstrasse 11, CH-8032, Zürich, Switzerland.

Tel: +41-44-6345600Ｆax: +41-44-6344305Ｅmail: mutluozcan@hotmail.com 
Implantology has demonstrated to be an effective solution in the treatment of edentulous patients ${ }^{1}$ The evidence have shown excellent success as well as subsequent improvement in the quality of life for the patients. ${ }^{2,3}$

The implant-bone interface is not resilient, therefore the stress by the absence of a correct fit for implant supported dental prostheses does not dissipate over time due to the ankylotic nature of osseointegration. That confirms the need of an accurate connection between the implant and the prosthesis. ${ }^{4}$

In addition, scientific literature has used the term "passive fit" like a total lack of tension between the implant and the framework. Although this basic definition is very under stable, a more concrete or specific aspect of this "passive fit" seems to be difficult issue of agreement between the different authors ${ }^{5-12}$

A prosthesis misfit can result in mechanical and biological complications. ${ }^{6-7}$ It is believed that biological complications such as loss of osseointegration and marginal bone may arise from a non accurate fitting prosthesis. ${ }^{2-3-4}$ Nevertheless there is no consensus on the real reason for marginal bone loss around the implants. $^{2}$ Some authors claim that the main cause for marginal bone loss is periimplantitis ${ }^{8,9}$ whereas others attribute it to adverse loading. ${ }^{10}$

It has been shown that stressed introduced by misfit was comparable to that related occlusal forces; therefore, framework-implant misfit should be carefully considered to ensure the reliability of the prosthetic system. Screw loosening, fracture of the prosthesis or implant components and occlusal inaccuracy, have been reported as mechanical complications. ${ }^{2-3-11-12}$

Achieving an absolute passive fit has been reported to be practically impossible. ${ }^{13,14,15}$ Nevertheless, it is still universally accepted that the prosthesis misfit should be minimized. ${ }^{1-2}$ 
Because of the many steps involved in constructing implant prosthesis, errors seem to be unavoidable. As the first step in the fabrication of the implant superstructure, a reliable impression transfer procedure is vital to avoid subsequent correction. ${ }^{3}$ Several implant impression studies have reported that working casts fail to exactly replicate the original situation. ${ }^{16,17}$ The introduction of computer-aided design/Computer aided manufacturing (CAD/CAM) technology in dentistry has resulted in a more accurate manufacturing of prosthetic frameworks, greater accuracy of dental restorations and implant supported prosthesis in particular ${ }^{18}$.

Ortorp and Jemt demonstrated improvement of the accuracy and precision of fit with CAM frames over conventional wax casting techniques. Nevertheless, these techniques are based on scanning procedures of a cast that was produced after conventional impression taking. ${ }^{19-20}$

Digital impressions have turned up with to avoid the problems arisen from the conventional impressions. ${ }^{21}$ Since Mörmann and Branderstini developed the concept of digital impression into the first device CEREC (Chairside Economical Restoration of Esthetic Ceramics) in 1985 there has been little development regarding this technology for direct digital impressions. It has not been until recent years that research and development sectors at many companies have improved the technologies and created in-office intraoral scanners that are increasingly user-friendly and produce precisely fitting dental restorations. These systems are capable of capturing three-dimensional virtual images of teeth, implant scan bodies and implant abutments. After that, from these images it possible to produce by using CAD/CAM systems (Stereolithography or rapid prototyping ) accurate master models for the restorations.

CEREC (Sirona Dental Systems, Charlotte, LLC) E4D (D4D Technologies, Texas), iTero (Cadent, Carlstadt, NJ) and Lava ${ }^{\mathrm{TM}}$ COS (3M ESPE, St Paul, MN) are the main systems available in the market. E4D is just available in the United States. CEREC and E4D come with a small milling unit to be used in-office. The rest continue the restorative workflow in the laboratory. 
There are also other systems, still not totally implemented such as Cyrtina ${ }^{\circledR}$ (Clon 3D), IOIDIS ${ }^{\circledR}$, Direct Scan ${ }^{\circledR}$ (HintEls), TRIOS ${ }^{\circ}$ (3 Shape), etc.

The indications of the intraoral scanners remain limited. Onlays, inlays, crowns, 3-4 unit bridges (depending on the system), veneers are the treatment possibilities that all of the systems in the market have. Single implants, digitalizing a scan body or a specific healing abutment (Encode system, Biomet 3i, Palm Beach Gardens, FL, USA), are available recently but not in all countries.

There is a very scarce knowledge about the accuracy, behavior and potential of the intraoral scanners systems.

The aim of this study therefore was to evaluate clinically for the first time, the possibility to obtain an accurate CAD/CAM implant framework over 6 implants using experimental prototype scan bodies and a Chairside Intraoral Scanner based on the principle of active (optical) wavefront sampling.

\section{MATERIALS AND METHODS.}

A 64-year-old completely edentulous male patient without any remarkable medical aspect was treated with dental implants.

Six implants Exfeel External (Megagen Implant Co., Ltd Korea) were place with a flap surgery and an immediate loading hybrid resin prosthesis was made the same day as a temporary restoration. 
Two and a half months later the restoration was removed (Fig. 1). Six abutments ( $8 \mathrm{~mm}$ high and had a diameter of $4 \mathrm{~mm}$ ) milled from polyether ether Ketone (PEEK) were used as scanning abutments. (Fig. 2) These abutments were specially designed using Createch (Createch Medical SL, Mendaro, Spain).

\section{Digital impression}

The Lava ${ }^{\mathrm{TM}}$ C.O.S is an intraoral scanner based on the principle of active (optical) wavefront sampling. The camera uses blue light emitting diode (L.E.D.) acquisition technology, and captures continuous 3D video images and creates a volume model in real-time in the computer monitor ${ }^{22}$. (Fig. 3)

Provided this case required the maximum accuracy the scan was done according to a specific $3 \mathrm{M}$ High Accuracy scanning protocol in which the scanner was manually calibrated at the before and after scanning the patient.

Titanium dioxide powder was applied over gingiva and rest of the jaw as suggested by the manufacturer except for the abutments that the powder applied was minimal in order to achieve as much accuracy as possible. A full arch lower scan was completed and the data was sent to 3M ESPE. (Fig. 4)

\section{Data processing}

From the intraoral scanning procedure, a stereolithographic (STL) file containing the information of the 3D location of the implants as well as the shape of the soft tissue was achieved.

The data obtained from the Lava COS was enhanced and calibrated by 3M ESPE and Createch Medical in order to achieve its maximum accuracy using the manual calibration done at the digital impression moment.

\section{Design and milling process of the structure}


The STL file was received by the CAD/CAM center Createch Medical (Createch SL, Mendaro, Spain) where it was imported with a CAD software to proceed with the restoration and model design.

\section{Model manufacturing}

Once the design of the digital model was finished, (Fig. 5) the STL data was sent for manufacturing by means of Rapid Prototyping containing conventional replicas in it. (Fig. 6)

\section{Teeth try in}

From the SLA model a resin teeth try-in was made and assessed in the practice. Subsequently the resin teeth were digitized obtaining an STL file of the final shape of the restoration.

The STL file of the teeth was transferred through the internet to the CAD/CAM center (Createch Medical SL, Mendaro, Spain). There the file was imported and connected digitally to the intraoral scanner STL file. From that overlap of the digital data the most convenient design for the titanium structure to support the acrylic was calculated, designed and fabricated. (Fig. 7)

Grade 5 Extra Low Interstitial (ELI) titanium was chosen as the material for the structure and milled with a 5 axis CNC milling machine.

\section{Structure try-in. Fit evaluation}

In order to verify the fit, the implant-supported structure was placed over the implants and an alternate finger pressured was applied. Neither rocking, nor saliva movements in the supragingival implants were detected visually or by tactile contact. A Sheffield test (one screw test) was carried out, and no movement was detected after placing the screw at the opposite place of the structure. A 60 microns explorer was used in order to examine the fit before and after placing the screw and no gap was detected. At last, all the screws were tested, 
following the screw resistance test explained in the literature, and not pressure was felt in the fingers while screwing any of them. ${ }^{23}$ (Fig. 8)

\section{Finishing the prosthesis}

The prosthesis was finished following the conventional procedure and screwed in the implants. (Fig. 9)

\section{DISCUSSION}

This case report describes a method that it is possible to take a multiple implant digital impression with the Lava ${ }^{\mathrm{TM}} \mathrm{COS}$ and fabricate a CAD/CAM structure from it achieving optimal clinical result.

\section{Digital Impressions}

There has been a general skepticism within the specialists in optical scanners of the Industry about the intraoral scanners being able to achieve short-term the accuracy that is needed for this kind of treatment. This is because, as oppose to extraoral scanners, the Intraoral devices lack fix references. So they work overlapping the photos that they capture. Every overlap has an inherent error. Thus, the more distance and the more overlaps are made the bigger the error would be. That would explain why the accuracy results for single crowns are easy to achieve while full arch implant impression constitute a much bigger challenge.

When taking a digital impression for a multiple implant-supported prosthesis, the steps, displacements and factors affecting the accuracy of the master cast are reduced substantially. The impression procedure becomes significantly more comfortable for the patient and the dentist, less time consuming, and more predictable. It is possible to stop in the middle of the procedure if needed and keep going just drying and powdering again the surface. Besides, the impression can be kept in the system, to be used again if required, without taking up extra room. 
Scarce data is published regarding digital devices accuracy. The studies published at the moment compare single crowns for teeth, made from a conventional impression or using an intraoral device finding better results for the digital process in fit and contact points. ${ }^{24,25}$

\section{Current prosthetic workflow}

It has been widely argued that the current clinical and laboratory procedures employed for framework fabrication are inadequate to provide passive fit for implant-supported structures. ${ }^{17,26,27,28,29}$

Implant location, depth, connection type and angulation, Impression technique and material, dimensional stability of the casting material selected to fabricate de model, splinting technique and material, constitute factors affecting the accuracy of the impression and the master model. ${ }^{5,6,30,3132}$

Four kinds of displacement of implant components can be introduced when making a definitive cast. The first is the displacement of each impression coping on the mating surface of each abutment across the machining tolerance range. The second is the displacement of each impression coping resulting from the impression technique or the material used. The third is the displacement of abutment replicas on fitting surface of each impression coping in the impression tray within the range of machining tolerance. The fourth is the displacement of each analogue in the definitive cast because of the dimensional change of the dental stone. ${ }^{30}$

The accuracy and biomechanical behavior of the resultant prosthesis may be compromised by, among others, accumulated errors in the laboratory procedure. ${ }^{33}$ Cast frameworks are likely to suffer distortion, marginal misfit, and/or air entrapment. ${ }^{34,35}$ 
The accuracy of the fit between a framework and implants is difficult to assess clinically. Various methods have been suggested in the literature but none have gained full acceptance as a precise standard test. ${ }^{36}$ In this case report several methods have been used as recommended in the literature trying to be as objective as possible. ${ }^{37}$ Finger pressure was used as an immediate method to check if there was any fulcrum o distortion. As most of the implant-prosthesis connections were juxta or supragingival it was possible to observe if saliva movements were taking place. As described in the literature, the visual inspection is highly dependent on the clinician, manual dexterity, etc a 60 microns explorer was used to analyze the fit. No horizontal discrepancies or gaps were detected in the structure. Also this was tested after applying the Sheffield test and again, no gap was felt.

A series of periapical Rx were done, but they were not perfectly parallel so they were discarded as an objective data to analyze the fit.

Also the resistance of the rest of the screws was tested, and the authors did not feel any resistance while screwing, which was found surprising.

\section{$\underline{C A D / C A M}$}

In recent years, a variety of $\mathrm{CAD} / \mathrm{CAM}$ systems and materials have been introduced in the field of restorative dentistry. It has been claimed that in addition to cost-effectiveness, the mayor advantage of a CAD/CAMfabricated restoration would be the passive fit of the framework. ${ }^{38},{ }^{39}$ In qualitative studies comparing CAD/CAM systems with conventional methods for framework fabrication with respect to accuracy or fit, or clinical performance, the authors claimed comparable or even better results for CAD/CAM techniques in

general. ${ }^{40}$ In some studies the authors express the opinion that the results were not more favorable for the $\mathrm{CAD} / \mathrm{CAM}$ groups due to the inaccuracies of impression making and cast fabrications, and found the intraoral impression devices as a very promising approach. ${ }^{41,16}$ 
Notwithstanding the accuracy of CAD/CAM systems for fabricating metallic structures, casting technologies continue to be more frequently used largely because of economic reasons. ${ }^{33}$

This technical report constitutes a test of the capability of a digital device base on active wavefront sampling technology to generate an accurate enough digital impression with which it was possible to get a precise fitting 6 screwed implant prosthesis. However, this should be developed further during the following years and tested in different scenarios to confirm that this can be achieved consistently.

$\mathrm{CAD} / \mathrm{CAM}$ technology is developing fast within dentistry. Being able to take intraoral impressions of multiple implants intraorally may constitute soon a generalized powerful tool to achieve the pursued passive fit predictably for our restorations.

\section{ACKNOWLEDGEMENTS}

The authors wish to thank Createch Medical for their technical expertise and the valuable discussions, Alberto Alvarez for his technical guidance and support during the process and 3M ESPE for the technical support with the scanner.

\section{DISCLOSURE}

The authors disclose no conflict of interests. 


\section{REFERENCES}

1. Chung WE, Rubenstein JE, Phillips KM, et al. Outcomes assessment of patients treated with osseointegrated dental implants at the University of Washington Graduate Prosthodontic Program, 1988 to 2000. Int J Oral Maxillofac Implants. 2009;24:927-935.

2. Zarb G, Schmitt A. Implant prosthodontic treatment options for edentulous patients. J Oral Rehabil $1995 ; 22: 661-671$.

3. Zurdo J, Romão C, Wennström JL. Survival and complication rates of implant-supported fixed partial dentures with cantilevers: a systematic review. Clin Oral Implants Res. 2009;20 Suppl 4:59-66.

4.Gomes EA, Assunção WG, Tabata LF, et al. Effect of passive fit absence in the prosthesis /implant/retaining screw system: a two-dimensional finite element analysis. J Craniofac Surg. 2009;20:2000-2005.

5. Jo SH, Kim KI, Seo JM, et al. Effect of impression coping and implant angulation on the accuracy of implant impressions: an in vitro study. J Adv Prosthodont. 2010;2:128-133

6. Lee H, So JS, Hochstedler JL, et al. The J Prosthet Dent. 2008;100:285-291.

7. Yamamoto E, Marotti J, de Campos TT, et al. Accuracy of four transfer impression techniques for dental implants: a scanning electron microscopic analysis. Int J Oral Maxillofac Implants. 2010;25:1115-1124.

8. Roos-Janaker AM, Lindahl C, Renvert H, et al. Nine-to-fourteen year follow up of implant treatment. Part II: Presence of peri-implant lesions. J Clin Periodontol. 2006;33:290-292.

9. Fransson C, Lekholm U, Jemt T, et al. Prevalence of subjects with progressive bone loss at implants. A 5-20 year retrospective study. Clin Oral Implant Res. 2005;16:440-446.

10 Taylor TD, Agar JR, Vogiatzi T. Implant prosthodontics: current perspective and future directions. Int J Oral Maxillofac Implants. 2000;15:66-75.

11. Lee HJ, Lim YJ, Kim CW, et al. Accuracy of a proposed implant impression technique using abutments and metal framework. J Adv Prosthodont. 2010;2:25-31. 
12. Taylor TD. Prosthodontic problems and limitations associated with osseointegration. J Prosthet Dent. 1998;79:74-78.

13. Karl M, Graef F, Heckmann S, et al. A Methodology to Study the Effects of Prosthesis Misfit Over Time: An In Vivo Model. Int J Oral Maxillofac Implants. 2009;24:689-694.

14. Jager K, Wilrz J. Mandibular hybrid dentures with 4 implants. An in vitro stress analysis. Schweiz Monastsschr Zahnmed. 1994;104:1489-1494.

15. Tan KB. The clinical significance of distortion in implant prosthodontics: Is there such a thing as passive fit? Ann Acad Med Singapore. 1995;24:138-157.

16. Eliasson A, Ortorp A. The Accuracy of an Implant Impression Technique Using Digitally Coded Healing Abutments. Clin Implant Dent Relat Res. 2012;14:30-38.

17. Del'Acqua MA, Arioli-Filho JN, Compagnoni MA et al. Accuracy of impression and pouring techniques for an implant-supported prosthesis. Int J Oral Maxillofac Implants. 2008;23:226-236.

18. De la Cruz JE, Funkenbusch PD, Ercoli C, et al. Verification jig for implant-supported prosthesis: A comparison of standard impressions with verification jigs made of different materials. J Prosthet Dent. 2002;88:329-336.

19. Ortorp A, Jemt T. Clinical experiences of CNC-milled titanium frameworks supported by implants in the edentulous jaw: 1-year prospective study. Clin Implant Dent Relat Res. 2000;2:2-9.

20. Ortorp A, Jemt T, Bäck T, et al. Comparisons of precision of fit between cast and CNC-milled titanium implant frameworks for the edentulous mandible. Int J Prosthodont. 2003;16:194-200.

21. Birnbaum NS, Aaronson HB. Dental Impressions Using 3D Digital Scanners: Virtual Becomes Reality. Compend Contin Educ Dent. 2008;29:494-505.

22. Kachaha PR, Geissberger MJ. Dentistry a la Carte: In office CAD/CAM Technology. J Calif Dent Assoc 2010;38:323-330.

23. Kan JY, Rungcharassaeng K, Bohsali K, et al. Clinical methods for evaluating implant framework fit. $J$ Prosthet Dent. 1999;81:7-13 
24. Syrek A, Reich G, Ranftl D,et al. Clinical evaluation of all-ceramic crowns fabricated from intraoral digital impressions based on the principle of active wavefront sampling. J Dent. 2010;38:553-559.

25. Henkel GL. A comparison of fixed prostheses generated from conventional vs digitally scanned dental impressions. Compend Contin Educ Dent. 2007;28:422-424, 426-428, 430-431.

26. Lee HJ, Lim YJ, Kim CW, et al. Accuracy of a proposed implant impression technique using abutments and metal framework. J Adv Prosthodont 2010;2:25-31.

27 Lee H, Ercoli C, Finkenbusch PD, et al. Effect of subgingival depth of implant placement on the dimensional accuracy of the implant impression: an in vitro study. J Prosthet Dent. 2008;99:107-113.

28. Lee H, So JS, Hochstedler JL, et al. The accuracy of implant impressions: a systematic review. J Prosthet Dent. 2008;100:285-291.

29. Filho HG, Mazaro JV, Vedovatoo E, et al. Accuracy of impression techniques for implants. Part 2 Comparison of splinting techniques. J Prosthodont. 2009;18:172-176.

30. Kim S, Nicholls JI, Han CH, et al. Displacement of implant components from impressions to definitive casts. Int J Oral Maxillofac Implants. 2006;21:747-755.

31. Lee H, Ercoli C, Finkenbusch PD et al. Effect of subgingival depth of implant placement on the dimensional accuracy of the implant impression: an in vitro study. J Prosthet Dent. 2008;99:107-113.

32 Lee H, So JS, Hochstedler JL, et al. The accuracy of implant impressions: a systematic review. J Prosthet Dent. 2008;100:285-291.

33. Cheng WW, Ju CP, Lin JH. Structure, castability and mechanical properties of commercially pure and alloyed titanium cast in graphite mould. J Oral Rehabil. 2007;34:528-540.

34. Oyagüe RC, Turrión AS, Toledano M, et al. In vitro vertical misfit evaluation of cast frameworks for cement-retained implant-supported partial prosthesis. J Dent. 2009;37:52-58.

35. Oyagüe RC, Osorio R, Lynch C, et al. Effect of alloy type and casting technique on the fracture strength of implant-cemented structures. Med Oral Patol Oral Cir Bucal. 2011;1;16:e619-625. 
36. Yanase R, Binon P, Jemt T, et al. How do you test a cast framework fit for a full-arch fixed implantsupported prosthesis? Int J Oral Maxillofac Implants. 1994;9:469-474.

37. Abduo J, Bennani V, Waddell N, et al. Assessing the fit of implant fixed prostheses: a critical review. Int $J$ Oral Maxillofac Implants. 2010;25:506-515.

38. Parel SM. The single-piece milled titanium implant bridge. Dent Today. 2003;22(2):96-99.

39. Mitrani R, Vasilic M, Bruguera A. Fabrication of an implant-supported reconstruction utilizing CAD/CAM technology. Pract Proced Aesthet Dent. 2005;17:71-78.

40. Takahashi T, Gunne J. Fit of implant frameworks: an in vitro comparison between two fabrication techniques. J Prosthet Dent. 2003;89:256-260.

41. Karl M, Taylor TD. Effect of material selection on the passivity of fit of implant supported restorations created with computer-aided design/computer-assisted manufacture. Int J Oral Maxillofac Implants. 2011; 26:739-745. 


\section{LEGENDS}

Fig.1. Baseline of the prosthetic phase, two and a half months after the surgery.

Fig. 2. Scanning PEEK abutments for the intraoral impression with applied powder as indicated by the manufacturer.

Fig. 3. Lava ${ }^{\mathrm{TM}}$ Chairside Oral Scanner (C.O.S) based on active wavefront sampling technology.

Fig. 4. The STL data obtained from the digital impression.

Fig. 5. Designing process of the model with a CAD software. Virtual location of the implants obtained from the digitalized scan bodies. Soft removable tissue design and the location of the replicas.

Fig. 6. Fabricated model by means of Rapid Prototyping, containing the implant replicas and removable soft tissue. The model is only use in order to add the resin and the occusal relation.

Fig. 7a. STL data obtained from the teeth try-in overlap with the model to calculate an appropriate structure design.

Fig. 7b. Sections of the digital process. Teeth try-in, implant structure, soft tissue and implant model.

Fig. 7c. Final anatomical design of the structure.

Fig. 8a. Try-in of the titanium structure obtaining accurate fit.

Fig. 8b. Panoral X-ray of the structure try-in.

Fig. 9. Metal resin hybrid implant prosthesis finished placed in the SLA model. 
14.01.14

Fig 1

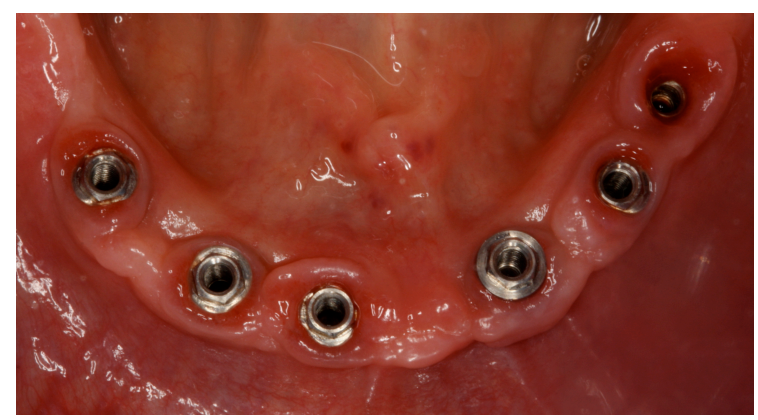

Fig 2

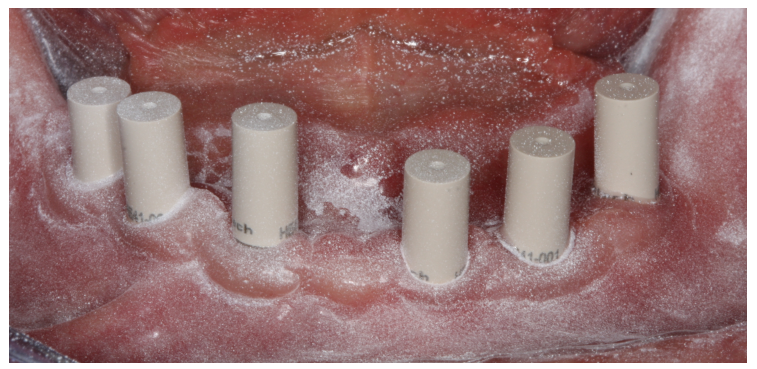


14.01.14

Fig 3

Fig 4

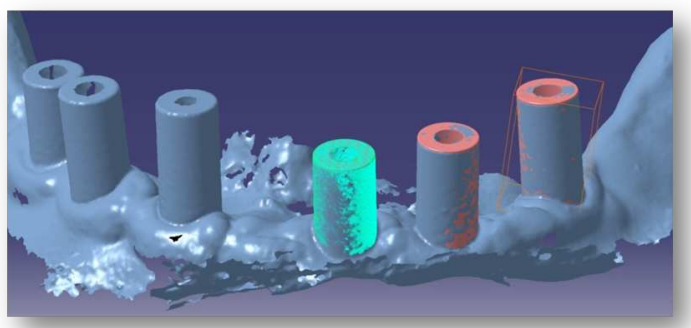


14.01.14

Fig 5

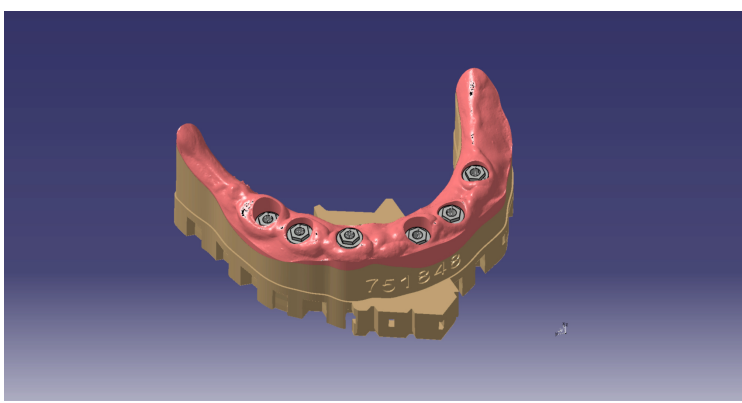

Fig 6

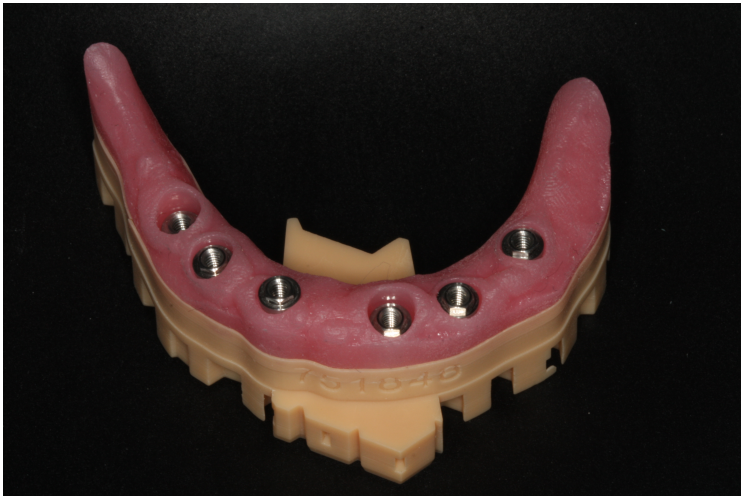


14.01.14

Fig $7 a$

Fig $7 b$

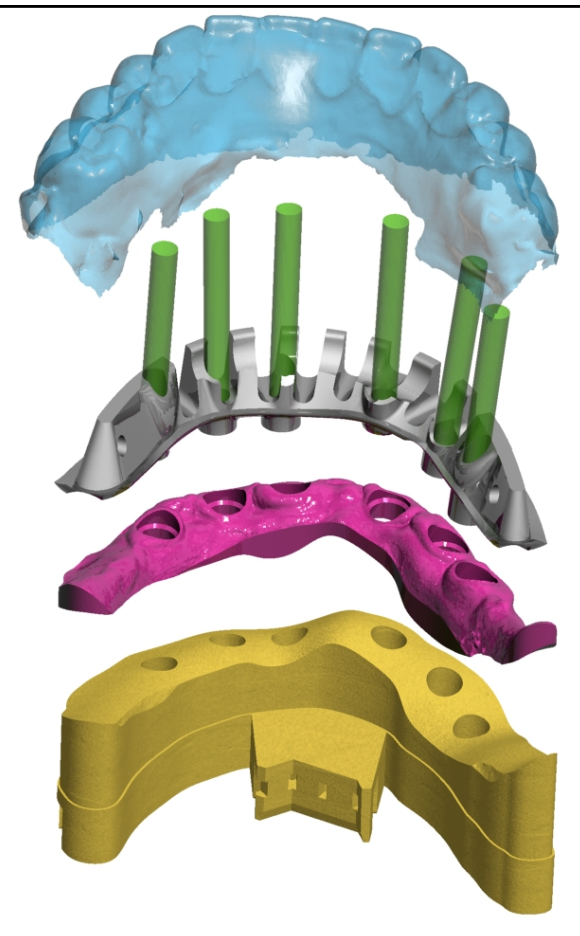


14.01.14

Fig 7c

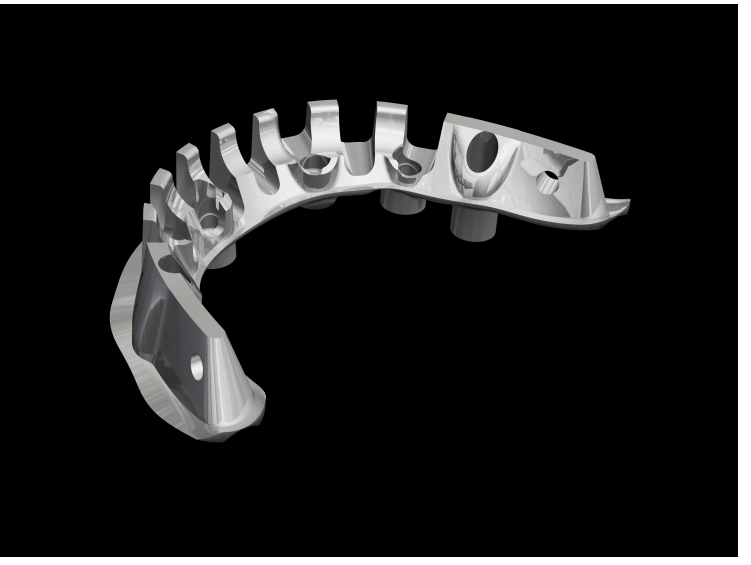

Fig $8 a$

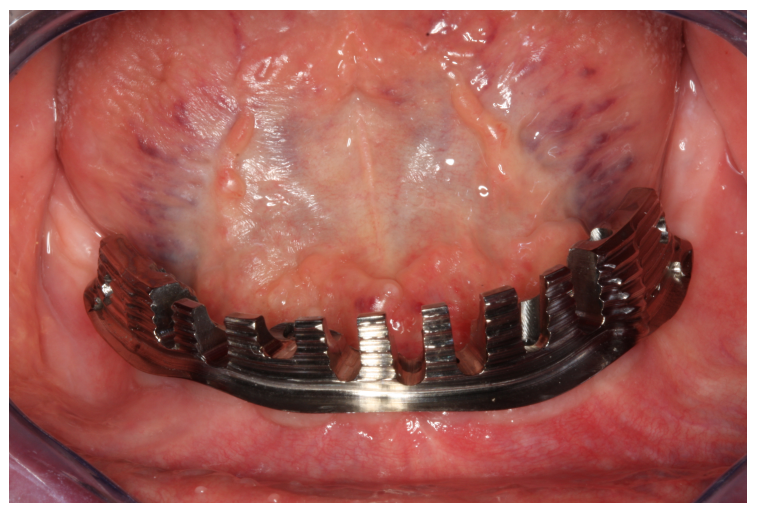


14.01.14

Fig 8b

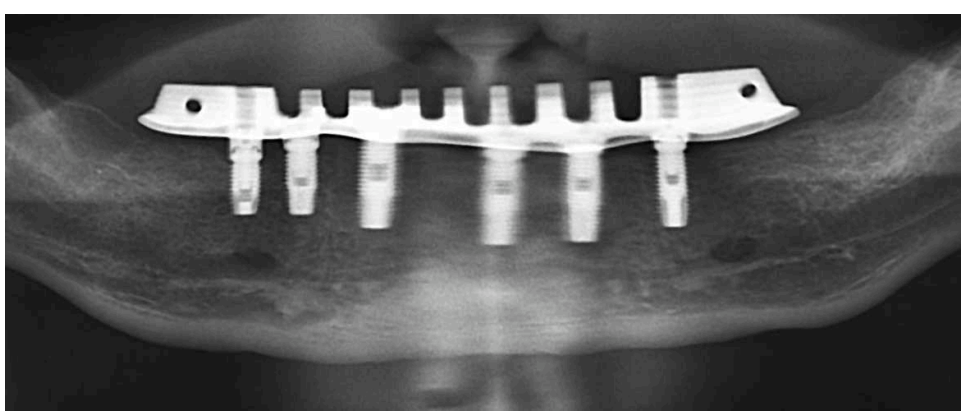

Fig 9

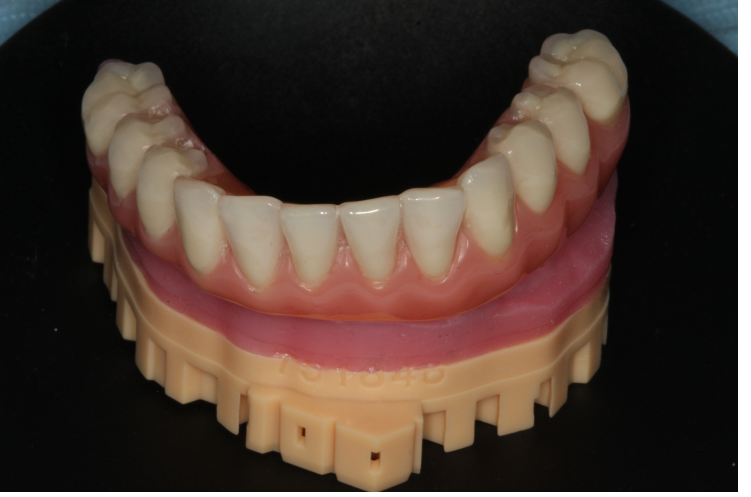

